\title{
Evaluation of hepatectomy and palliative local treatments for gastric cancer patients with liver metastases: a propensity score matching analysis
}

\author{
Jiyang Li ${ }^{1, *}$, Kecheng Zhang ${ }^{1, *}$, Yunhe Gao ${ }^{1}$, Hongqing $\mathrm{Xi}^{1}$, Jianxin Cui ${ }^{1}$, Wenquan \\ Liang ${ }^{1}$, Aizhen Cai ${ }^{1}$, Bo Wei ${ }^{1}$ and Lin Chen ${ }^{1}$ \\ ${ }^{1}$ Department of General Surgery, Chinese People's Liberation Army General Hospital, Beijing 100853, China \\ *These authors have contributed equally to this work \\ Correspondence to: Lin Chen, email: chenlin_301bj@163.com \\ Bo Wei, email: weibobj301@sina.com \\ Keywords: stomach neoplasms, liver, hepatectomy, radiofrequency ablation, transarterial chemoembolization \\ Received: January 17, $2017 \quad$ Accepted: May 23, $2017 \quad$ Published: June 27, 2017 \\ Copyright: Li et al. This is an open-access article distributed under the terms of the Creative Commons Attribution License 3.0 \\ (CC BY 3.0), which permits unrestricted use, distribution, and reproduction in any medium, provided the original author and source \\ are credited.
}

\section{ABSTRACT}

Background: The optimal treatments for gastric cancer with liver metastases (GCLM) remain controversial. This study aimed to evaluate the efficacy of hepatectomy, RFA and TACE as local treatments for GCLM.

Methods: From 2001 to 2015, 119 consecutive patients who received multidisciplinary treatments based on curative gastrectomy and local treatments (hepatectomy, RFA and TACE) for liver metastases were enrolled in this retrospective cohort study. Patients were divided into Group A (46, hepatectomy) and Group B (73, either or both RFA and TACE). Propensity score matching analysis was employed.

Results: The propensity model revealed that hepatectomy was associated with significantly longer OS compared with either or both RFA and TACE $(P=0.021)$. The 1-, 3- and 5-year OS rates were $80.5 \%, 41.5 \%$ and $24.4 \%$, respectively in Group A; and $85.4 \%, 21.9 \%$ and $12.2 \%$, respectively in Group B. Subgroup analyses indicated that hepatectomy was associated with significantly longer long-term survival compared with TACE $(P=0.033)$ and $R F A(P=0.010)$. TACE had a similar efficacy as RFA $(P=0.518)$, but with significantly lower costs $(P=0.014)$ in for patients with metachronous GCLM.

Conclusion: Hepatectomy is the optimal local treatment for GCLM when surgical RO resection is intended. TACE attained a similar prognosis as RFA with relatively high cost-effectiveness, particularly for patients with metachronous GCLM.

\section{INTRODUCTION}

Gastric cancer is the fourth most common tumor and the second most common cause of cancer-related death worldwide; the highest incidence is in Eastern Asia, where approximately 1,000,000 people per year are affected [1,2]. Hematogenous dissemination is one of the main methods by which gastric cancer metastasizes; the liver is the organ most frequently involved, with an incidence of $30 \%-50 \%$ [3]. Moreover, at the time of diagnosis, approximately $35 \%$ of patients have distant metastases, while $4 \%-14 \%$ have metastatic disease in the liver [4]. Gastric cancer liver metastases (GCLM) are associated with shorter survival $[5,6]$. Surgical techniques and perioperative management have improved, and many patients with GCLM benefit from surgery [7-9]. The Japanese working group reached the conclusion that hepatectomy should be considered for carefully selected patients with GCLM[10]. To some extent, complete surgical resection is the only form of therapy with curative intent for GCLM.

Unlike colorectal liver metastasis and because of the aggressively infiltrative biological behavior of 
gastric cancer, liver metastases from gastric cancer are mostly characterized by multiple lesions that are diffusely distributed on both hepatic lobes and are combined with peritoneal dissemination, lymph nodes, or other distant organ metastases $[6,11]$. Only $0.3 \%-2.4 \%$ of patients with GCLM are candidates for hepatic resection [4]. Therefore, the optimal local treatment for liver metastases remains controversial. Radiofrequency ablation (RFA) and transarterial chemoembolization (TACE) are effective and low risk, with more expanded indications in patients with liver metastases. Further, RFA and TACE can repeatedly administered to gastric cancer patients with unresectable liver metastases $[12,13]$.

Although a randomized controlled trial is best to evaluate the curative effect of therapy, it is unlikely to recruit patients who would agree to random assignment to complicated procedures with obvious differences. Propensity score matching (PSM) analysis can overcome selection bias, to the extent possible, to increase the evidence level of a nonrandomized observational study [14].

It is therefore imperative to use the PSM model to evaluate different methods for the local treatment of liver metastases in patients with gastric cancer. In the present study, we assessed the optimal treatment for GCLM by conducting an analysis of a cohort of consecutive patients who underwent gastrectomy accompanied by local treatment for liver metastases.

\section{RESULTS}

\section{Baseline characteristics}

The 119 patients enrolled in the study were all Han Chinese, 101 men and 18 women (5.6:1) with a mean age of 58.4 years (range, 20-83 years). Their occupations included public service $(28,23.5 \%)$, professional technicians $(11,9.2 \%)$, commercial staff $(19,16.0 \%)$, production staff $(27,22.7 \%)$, military $(9,7.6 \%)$ and others $(25,21.0 \%)$. Their educational levels were as follows: illiterate $(0,0 \%)$, elementary education or above $(12,10.1 \%)$, secondary education or above $(79,66.4 \%)$, and bachelor's degree or above $(28,23.5 \%)$. Marital status was as follows: married $(95,79.8 \%)$, loss of spouse $(16,13.4 \%)$, divorced $(7,5.9 \%)$, and unmarried $(1,0.9 \%)$.

Data for the baseline clinicopathologic variables available in the database were as follows: sex, age, body mass index, Karnofsky Performance Scale (KPS) score, characteristics of the primary gastric tumor (location, size, Borrmann classification, degree of histologic differentiation, depth of invasion, lymph node metastasis), characteristics of hepatic metastases (type, number, size and distribution), neutrophil to lymphocyte ratio (NLR), presence of carcinoembryonic antigen (CEA), alpha-fetoprotein (AFP) level, and types of treatment. Baseline characteristics of all patients before matching are summarized in Table 1 . Patients with GCLM who underwent surgical resection (Group A) were significantly younger and had higher AFP levels compared with those of the patients administered palliative local treatments, RFA, TACE, or both (Group B) (Both $\mathrm{P}<0.05)$. Group B included more patients with metachronous liver metastases compared with those in Group A (32 vs 6, $\mathrm{P}<0.001)$. PSM identified 41 patients from each treatment group with similar characteristics (all P>0.05; Table 2 ).

\section{Factors associated with overall survival (OS)}

Univariate analysis of overall survival of all patients revealed that diffuse infiltration according to the Borrmann classification and synchronous liver metastases were significantly associated with increased mortality rates (both $\mathrm{P}<0.05$; Table 3 ). The data acquired using multivariate Cox proportional hazards model revealed that only diffuse infiltration of the Borrmann classification $(\mathrm{P}=0.002$; Table 3 ) was an independent prognostic predictor of a poor long-term outcome.

Apart from diffuse infiltration of the Borrmann classification $(\mathrm{P}=0.003)$ as an adverse effect, univariate analysis of the matched cohort revealed that hepatectomy was associated with shorter survival. Further, the location of the primary gastric tumor significantly influenced prognosis ( $\mathrm{P}=0.045$; Table 3$)$, although this was excluded by the results of analysis using the Cox proportional hazards model ( $\mathrm{P}>0.05$; Table 3$)$. The protective effect of hepatectomy was uncertain with a marginal value $\mathrm{P}=0.052$ (Table 3). Diffuse infiltration of the Borrmann classification $(\mathrm{P}=0.024$; Table 3$)$ was an independent adverse prognostic predictor of OS.

\section{Survival analysis}

\section{All patients}

The mean overall survival time (OST) of the 119 patients was 40 months (range, 3-187 months), 43 months (range, 3-178 months) for the 46 patients in Group A and 37 months (range, 6-187 months) for the 73 patients in Group B. The 1-, 3- and 5-year survival rates were 79.5\%, $40.9 \%$, and $25.0 \%$, respectively, in Group A and 84.7\%, $23.7 \%$ and $15.3 \%$, respectively, in Group B. Kaplan-Meier survival analysis revealed similar OST between Groups $\mathrm{A}$ and $\mathrm{B}\left(\chi^{2}=3.514 ; \mathrm{P}=0.061\right.$; Figure $\left.1 \mathrm{~A}\right)$. There was no treatment-related mortality.

\section{Matched cohort}

Using PSM revealed that patients who underwent hepatectomy had significantly longer OST compared with those received palliative local treatments $\left(\chi^{2}=5.289\right.$; $\mathrm{P}=0.021$; Figure 1B). The 1-, 3- and 5-year OS rates were $80.5 \%, 41.5 \%$, and $24.4 \%$, respectively, in Group A and $85.4 \%, 21.9 \%$ and $12.2 \%$, respectively, in Group B. 
Table 1: Baseline characteristics of the whole patient cohort

\begin{tabular}{|c|c|c|c|}
\hline Characteristics & Group A $(n=46)$ & Group B $(n=73)$ & P-value \\
\hline Age (years) ${ }^{*}$ & $54.9 \pm 1.6$ & $60.0 \pm 1.3$ & 0.014 \\
\hline Sex & & & 0.110 \\
\hline Male & $36(78.3 \%)$ & $65(89.0 \%)$ & \\
\hline Female & $10(21.7 \%)$ & $8(11.0 \%)$ & \\
\hline $\operatorname{BMI}(\mathrm{kg} / \mathrm{m} 2)^{*}$ & $23.3 \pm 0.6$ & $23.3 \pm 0.5$ & 0.993 \\
\hline KPS scores & & & 0.222 \\
\hline $80-$ & $1(2.2 \%)$ & $5(6.9 \%)$ & \\
\hline $90-$ & $45(97.8 \%)$ & $68(93.1 \%)$ & \\
\hline $\begin{array}{l}\text { Gastric primary tumor } \\
\text { location }\end{array}$ & & & 0.488 \\
\hline Proximal & $12(26.1 \%)$ & $18(24.7 \%)$ & \\
\hline Middle & $12(26.1 \%)$ & $16(21.9 \%)$ & \\
\hline Distal & $17(37.0 \%)$ & $23(31.5 \%)$ & \\
\hline Total & $5(10.8 \%)$ & $16(21.9 \%)$ & \\
\hline $\begin{array}{l}\text { Size of gastric primary } \\
\text { tumor }(\mathrm{cm})^{\#}\end{array}$ & $5.7 \pm 0.6$ & $5.2 \pm 0.4$ & 0.447 \\
\hline Bormmann & & & 0.641 \\
\hline Mass & $2(4.3 \%)$ & $7(9.6 \%)$ & \\
\hline Ulcerative & $29(63.0 \%)$ & $48(65.8 \%)$ & \\
\hline Infiltrative ulcerative & $12(26.2 \%)$ & $16(21.9 \%)$ & \\
\hline Diffuse Infiltrative & $3(6.5 \%)$ & $2(2.7 \%)$ & \\
\hline $\begin{array}{l}\text { Degree of histologic } \\
\text { differentiation }\end{array}$ & & & 0.234 \\
\hline Well or moderately & $26(56.5 \%)$ & $28(38.4 \%)$ & \\
\hline Poorly or signet-ring cell & $20(43.5 \%)$ & $45(61.6 \%)$ & \\
\hline $\mathrm{T}$ & & & 0.976 \\
\hline $\mathrm{T} 1$ & $3(6.5 \%)$ & $7(9.7 \%)$ & \\
\hline $\mathrm{T} 2$ & $3(6.5 \%)$ & $5(6.8 \%)$ & \\
\hline $\mathrm{T} 3$ & $3(6.5 \%)$ & $5(6.8 \%)$ & \\
\hline $\mathrm{T} 4$ & $37(80.5 \%)$ & $56(76.7 \%)$ & \\
\hline $\mathrm{N}$ & & & 0.219 \\
\hline N0 & $5(10.9 \%)$ & $16(21.9 \%)$ & \\
\hline $\mathrm{N} 1$ & $8(17.4 \%)$ & $19(26.0 \%)$ & \\
\hline $\mathrm{N} 2$ & $12(26.1 \%)$ & $14(19.2 \%)$ & \\
\hline N3 & $21(45.6 \%)$ & $24(32.9 \%)$ & \\
\hline \multicolumn{4}{|l|}{ Type of liver metastases } \\
\hline Synchronous & $40(87.0 \%)$ & $41(56.2 \%)$ & $<0.001$ \\
\hline Metachronous & $6(13.0 \%)$ & $32(43.8 \%)$ & \\
\hline
\end{tabular}




\begin{tabular}{lccc}
\hline Characteristics & Group A $(\mathbf{n}=\mathbf{4 6})$ & Group B (n=73) & P-value \\
\hline Number of liver metastases & & & 0.394 \\
Isolated metastases & $18(39.1 \%)$ & $23(31.5 \%)$ & \\
$\quad$ Multiple metastases & $28(60.9 \%)$ & $50(68.5 \%)$ & 0.140 \\
H & & & \\
H1 & $23(50.0 \%)$ & $28(38.4 \%)$ & \\
H2 & $6(13.0 \%)$ & $5(6.8 \%)$ & 0.255 \\
H3 & $17(37.0 \%)$ & $40(54.8 \%)$ & 0.620 \\
Size of liver metastases $(\mathrm{cm})^{\#}$ & $3.8 \pm 0.5$ & $3.2 \pm 0.3$ & 0.329 \\
NLR & $3.5 \pm 0.9$ & $4.2 \pm 0.8$ & $\mathbf{0 . 0 3 1}$ \\
CEA (ug/L) & $18.4 \pm 5.6$ & $11.2 \pm 4.7$ & 0.537 \\
AFP (ug/L) & $41.8 \pm 20.1$ & $4.0 \pm 0.6$ & \\
Chemotherapy & & & \\
$\quad$ Postoperative & & $59(80.8 \%)$ & \\
chemotherapy & $35(76.1 \%)$ & $14(19.2 \%)$ & \\
Perioperative chemotherapy & $11(23.9 \%)$ & & \\
\hline
\end{tabular}

\section{Subgroup analysis}

To better explain the effect of these three local treatments, we compared the long-term outcomes of patients who received a single local treatment (hepatectomy, 46 patients; TACE, 45 patients; and RFA, 21 patients). The mean OST was 70 months for the 46 patients who

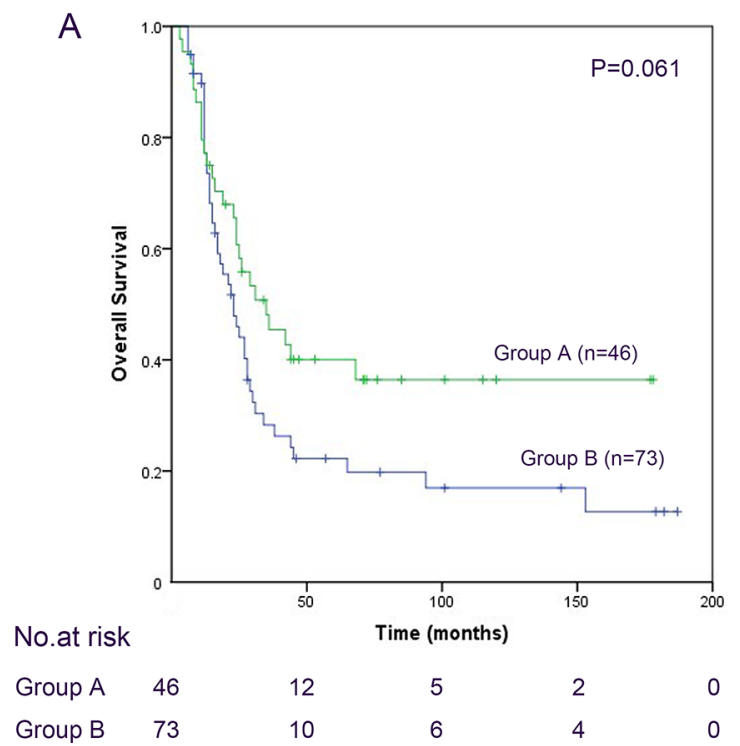

underwent hepatectomy, 54 months for the 45 patients received TACE, and 23 months for the 21 patients received RFA. The actuarial 1-, 3- and 5-year survival rates were $84.0 \%, 52.0 \%$ and $28.0 \%$, respectively, for hepatectomy; $86.1 \%, 27.8 \%$ and $19.4 \%$, respectively, for TACE; and $75 \%$, $6,3 \%$ and 0 , respectively, for RFA. Hepatectomy achieved

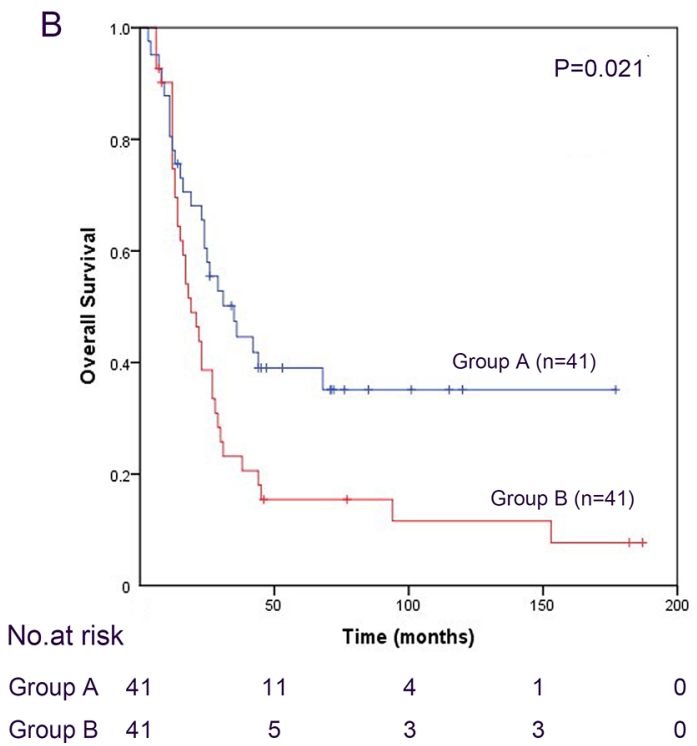

Figure 1: Cumulative overall survival was analyzed using the Kaplan-Meier method, and the differences in survival curves among the groups were compared using the log-rank test. (A) Overall survival of the 119 patients in Group A and Group B before propensity score matching analysis. Kaplan-Meier survival analysis revealed similar overall survival between Groups A and B. $(\chi 2=3.514 ; \mathrm{P}=0.061)$. (B) Overall survival of the 82 patients in Group A and Group B after propensity score matching analysis. Using PSM revealed that patients who underwent hepatectomy had significantly longer overall survival compared with those received palliative local treatments. $(\chi 2=5.289 ; \mathrm{P}=0.021)$ 
Table 2: Baseline characteristics of patients in the matched cohort

\begin{tabular}{|c|c|c|c|}
\hline Characteristics & Group A $(n=41)$ & Group B $(n=41)$ & P-value \\
\hline Age (years) ${ }^{*}$ & $54.2 \pm 1.7$ & $58.1 \pm 1.6$ & 0.110 \\
\hline Sex & & & 0.194 \\
\hline Male & $33(80.5 \%)$ & $38(92.7 \%)$ & \\
\hline Female & $8(19.5 \%)$ & $3(7.3 \%)$ & \\
\hline $\operatorname{BMI}(\mathrm{kg} / \mathrm{m} 2)^{*}$ & $22.9 \pm 0.6$ & $24.3 \pm 0.6$ & 0.118 \\
\hline KPS scores & & & 1.000 \\
\hline $80-$ & $1(2.4 \%)$ & $0(0)$ & \\
\hline $90-$ & $40(97.6 \%)$ & $41(100 \%)$ & \\
\hline $\begin{array}{l}\text { Gastric primary tumor } \\
\text { location }\end{array}$ & & & 0.886 \\
\hline Proximal & $10(24.4 \%)$ & $11(26.8 \%)$ & \\
\hline Middle & $11(26.8 \%)$ & $8(19.5 \%)$ & \\
\hline Distal & $15(36.6 \%)$ & $16(39.1 \%)$ & \\
\hline Total & $5(12.2 \%)$ & $6(14.6 \%)$ & \\
\hline $\begin{array}{l}\text { Size of gastric primary } \\
\text { tumor }(\mathrm{cm})^{\#}\end{array}$ & $5.5 \pm 0.7$ & $5.2 \pm 0.5$ & 0.682 \\
\hline Bormmann & & & 0.671 \\
\hline Mass & $2(4.9 \%)$ & $4(9.7 \%)$ & \\
\hline Ulcerative & $27(65.8 \%)$ & $28(68.3 \%)$ & \\
\hline Infiltrative ulcerative & $9(22.0 \%)$ & $7(17.1 \%)$ & \\
\hline Diffuse infiltrative & $3(7.3 \%)$ & $2(4.9 \%)$ & \\
\hline $\begin{array}{l}\text { Degree of histologic } \\
\text { differentiation }\end{array}$ & & & 0.098 \\
\hline Well or moderately & $20(48.8 \%)$ & $12(29.3 \%)$ & \\
\hline Poorly or signet-ring cell & $21(51.2 \%)$ & $29(70.7 \%)$ & \\
\hline $\mathrm{T}$ & & & 0.934 \\
\hline $\mathrm{T} 1$ & $4(9.7 \%)$ & $4(9.7 \%)$ & \\
\hline $\mathrm{T} 2$ & $4(9.7 \%)$ & $2(4.9 \%)$ & \\
\hline $\mathrm{T} 3$ & $3(7.3 \%)$ & $2(4.9 \%)$ & \\
\hline $\mathrm{T} 4$ & $30(73.3 \%)$ & $33(80.5 \%)$ & \\
\hline $\mathrm{N}$ & & & 0.221 \\
\hline N0 & $5(12.2 \%)$ & $8(19.5 \%)$ & \\
\hline N1 & $8(19.5 \%)$ & $14(34.2 \%)$ & \\
\hline $\mathrm{N} 2$ & $11(26.8 \%)$ & $11(26.8 \%)$ & \\
\hline N3 & $17(41.5 \%)$ & $8(19.5 \%)$ & \\
\hline \multicolumn{4}{|l|}{ Type of liver metastases } \\
\hline Synchronous & $36(87.8 \%)$ & $32(78.0 \%)$ & 0.379 \\
\hline Metachronous & $5(12.2 \%)$ & $9(22.0 \%)$ & \\
\hline
\end{tabular}

(Continued) 


\begin{tabular}{|c|c|c|c|}
\hline Characteristics & Group A $(n=41)$ & Group B $(n=41)$ & P-value \\
\hline Number of liver metastases & & & 0.492 \\
\hline Isolated metastases & $17(41.5 \%)$ & $13(31.7 \%)$ & \\
\hline Multiple metastases & $24(58.5 \%)$ & $28(68.3 \%)$ & \\
\hline $\mathrm{H}$ & & & 0.247 \\
\hline H1 & $20(48.8 \%)$ & $16(39.0 \%)$ & \\
\hline $\mathrm{H} 2$ & $6(14.6 \%)$ & $3(7.3 \%)$ & \\
\hline H3 & $15(36.6 \%)$ & $22(53.7 \%)$ & \\
\hline Size of liver metastases $(\mathrm{cm})^{\#}$ & $3.6 \pm 0.6$ & $3.1 \pm 0.4$ & 0.426 \\
\hline $\mathrm{NLR}^{\#}$ & $2.6 \pm 0.3$ & $3.7 \pm 0.7$ & 0.155 \\
\hline CEA (ug/L)\# & $19.9 \pm 6.9$ & $13.7 \pm 6.4$ & 0.519 \\
\hline $\mathrm{AFP}(\mathrm{ug} / \mathrm{L})^{\#}$ & $15.1 \pm 6.8$ & $4.7 \pm 0.8$ & 0.084 \\
\hline Chemotherapy & & & 0.806 \\
\hline $\begin{array}{l}\text { Postoperative } \\
\text { chemotherapy }\end{array}$ & $30(73.2 \%)$ & $29(70.7 \%)$ & \\
\hline $\begin{array}{l}\text { Perioperative } \\
\text { chemotherapy }\end{array}$ & $11(26.8 \%)$ & $12(29.3 \%)$ & \\
\hline
\end{tabular}

Values are expressed as the mean $\pm \mathrm{SD}$, or number (percentage). All of the tumor-related clinicopathologic data were obtained from postoperative pathological reports. BMI, body mass index; KPS, Karnofsky Performance Scale score. Size of gastric primary tumor indicates the maximal diameter of the primary gastric tumor. Hepatic metastases were classified as H1 (limited to one lobe), H2 (a few lesions scattered in both lobes) and H3 (multiple diffusely distributed metastatic lesions in both lobes). Continuous variables: * normal distribution, Pearson chi-square test; " non-normally distribution, the MannWhitney test. Value shown in bold is statistically significant $(\mathrm{P}<0.05)$.

significantly longer survival compared with the other two palliative local treatments $\left(\chi^{2}=6.843 ; \mathrm{P}=0.033\right.$; Figure 2). Comparison of the groups led to the same conclusion as follows: hepatectomy was significantly associated with OS compared with TACE $\left(\chi^{2}=4.538 ; \mathrm{P}=0.033\right.$; Figure 2$)$ and RFA $\left(\chi^{2}=6.647 ; \mathrm{P}=0.010\right.$; Figure 2$)$. The efficacy of TACE was similar to that of RFA $\left(\chi^{2}=0.418 ; \mathrm{P}=0.518\right.$; Figure 2$)$. The distribution of liver metastases is an important factor that influences prognosis. Therefore, we performed separate comparisons of the long-term outcomes of patients in Groups A and B in the H1, H2 and H3 subgroups. There were no statistical differences in the long-term survival of the subgroups $\left(\mathrm{H} 1, \chi^{2}=1.926, \mathrm{P}=0.165 ; \mathrm{H} 2, \chi^{2}=0.732\right.$, $\mathrm{P}=0.392 ; \mathrm{H} 3, \chi^{2}=2.663, \mathrm{P}=0.103$; Figure $3 \mathrm{~A}$ ), which may be explained by the small number of patients in each subgroup $(\mathrm{H} 1=36, \mathrm{H} 2=9, \mathrm{H} 3=37)$. Further, we found that the degree of liver metastases (one lobe vs two lobes) did not affect the prognosis of patients with GCLM in Groups A and B (one lobe, $\chi^{2}=1.926, \mathrm{P}=0.165$; two lobes, $\chi^{2}=2.919, \mathrm{P}=0.088$; Figure 3B).

\section{Financial cost}

We calculated the average treatment costs for patients with synchronous GCLM who received gastrectomy combined with hepatectomy, RFA, or both and patients with metachronous GCLM who received TACE, RFA or both as local treatments for liver metastases (Table 4). The results indicate that financial costs were similar for patients with synchronous GCLM ( $\mathrm{P}=0.164)$. However, TACE was significantly more cost-effective for patients with metachronous GCLM (TACE $=39,215$ RMB and RFA $=95,250$ RMB, $\mathrm{P}=0.014)$.

\section{DISCUSSION}

Oncologists have become increasingly interested in local treatments of patients with GCLM. Hepatectomy, RFA and TACE are all valuable therapeutic procedures. However, very limited data are available regarding the optimal management strategy. Here we investigated a cohort of gastric cancer patients with liver metastases only to clarify the effect of local treatments selection on long-term outcomes. Our results reveal that radical hepatectomy was very effective for treating certain patients with GCLM. TACE, an alternative local treatment, attained a similar prognosis as RFA with relatively high cost-effectiveness, particularly in metachronous GCLM patients. 
Table 3: Univariate and multivariate analysis for overall survival in patients.

\begin{tabular}{|c|c|c|c|c|}
\hline & \multicolumn{2}{|c|}{ Univariate } & \multicolumn{2}{|c|}{ Multivariate } \\
\hline & HR $(95 \% C I)$ & P-value & HR $(95 \% C I)$ & P-value \\
\hline \multicolumn{5}{|c|}{ All patients in the whole cohort $(n=119)$} \\
\hline Age (year) & $1.022(1.000-1.045)$ & 0.054 & & \\
\hline Sex & & 0.676 & & \\
\hline Male & 1.00 (Reference) & & & \\
\hline Female & $0.854(0.409-1.786)$ & & & \\
\hline $\operatorname{BMI}(\mathrm{kg} / \mathrm{m} 2)$ & $1.021(0.948-1.100)$ & 0.579 & & \\
\hline KPS & $0.996(0.915-1.083)$ & 0.916 & & \\
\hline Gastric primary tumor location & & 0.090 & & \\
\hline Proximal & 1.00 (Reference) & & & \\
\hline Middle & $0.539(0.275-1.056)$ & 0.072 & & \\
\hline Distal & $0.575(0.319-1.036)$ & 0.065 & & \\
\hline Total & $1.086(0.537-2.199)$ & 0.818 & & \\
\hline $\begin{array}{l}\text { Size of gastric primary tumor } \\
(\mathrm{cm})\end{array}$ & $0.985(0.912-1.064)$ & 0.698 & & \\
\hline Bormmann & & $<0.001$ & & $<0.001$ \\
\hline Mass & 1.00 (Reference) & & 1.00 (Reference) & \\
\hline Ulcerative & $0.971(0.298-3.165)$ & 0.961 & $0.971(0.298-3.166)$ & 0.961 \\
\hline Infiltrative ulcerative & $2.056(0.587-7.194)$ & 0.260 & $2.058(0.587-7.207)$ & 0.259 \\
\hline Diffuse infiltrative & $11.281(2.363-53.860)$ & 0.002 & $11.321(2.352-54.492)$ & 0.002 \\
\hline $\begin{array}{l}\text { Degree of histologic } \\
\text { differentiation }\end{array}$ & & 0.165 & & \\
\hline Well or moderately & 1.00 (Reference) & & & \\
\hline Poorly or signet-ring cell & $1.424(0.865-2.345)$ & & & \\
\hline $\mathrm{T}$ & & 0.828 & & \\
\hline $\mathrm{T} 1$ & 1.00 (Reference) & & & \\
\hline $\mathrm{T} 2$ & $1.244(0.350-4.413)$ & 0.736 & & \\
\hline $\mathrm{T} 3$ & $1.737(0.486-6.212)$ & 0.396 & & \\
\hline $\mathrm{T} 4$ & $1.409(0.604-3.284)$ & 0.427 & & \\
\hline $\mathrm{N}$ & & 0.554 & & \\
\hline N0 & 1.00 (Reference) & & & \\
\hline N1 & $0.895(0.425-1.882)$ & 0.770 & & \\
\hline $\mathrm{N} 2$ & $1.407(0.692-2.861)$ & 0.345 & & \\
\hline N3 & $1.249(0.623-2.503)$ & 0.531 & & \\
\hline Type of liver metastases & & 0.045 & & 0.964 \\
\hline Synchronous & 1.00 (Reference) & & 1.00 (Reference) & \\
\hline Metachronous & $0.567(0.325-0.991)$ & & $1.013(0.564-1.821)$ & \\
\hline
\end{tabular}

(Continued) 


\begin{tabular}{|c|c|c|c|c|}
\hline & \multicolumn{2}{|c|}{ Univariate } & \multicolumn{2}{|c|}{ Multivariate } \\
\hline & HR $(95 \% C I)$ & P-value & HR $(95 \% C I)$ & P-value \\
\hline Interval of metachronous & $0.970(0.940-1.002)$ & 0.062 & & \\
\hline Number of liver metastases & & 0.757 & & \\
\hline Isolated metastases & 1.00 (Reference) & & & \\
\hline Multiple metastases & $0.924(0.562-1.521)$ & & & \\
\hline $\mathrm{H}$ & & 0.474 & & \\
\hline H1 & 1.00 (Reference) & & & \\
\hline $\mathrm{H} 2$ & $1.483(0.714-3.028)$ & 0.291 & & \\
\hline $\mathrm{H} 3$ & $0.958(0.578-1.589)$ & 0.868 & & \\
\hline Size of liver metastases $(\mathrm{cm})$ & $0.973(0.866-1.093)$ & 0.645 & & \\
\hline NLR & $0.951(0.798-1.134)$ & 0.579 & & \\
\hline CEA & $0.995(0.977-1.013)$ & 0.604 & & \\
\hline RFA & $1.004(0.996-1.013)$ & 0.330 & & \\
\hline Chemotherapy & & 0.382 & & \\
\hline Perioperative chemotherapy & 1.00 (Reference) & & & \\
\hline Postoperative chemotherapy & $1.278(0.737-2.218)$ & & & \\
\hline Hepatectomy & $0.635(0.390-1.032)$ & 0.067 & & \\
\hline RFA & $1.033(0.616-1.733)$ & 0.903 & & \\
\hline TACE & $1.395(0.857-2.270)$ & 0.180 & & \\
\hline \multicolumn{5}{|c|}{ Patients in the matched cohort $(n=82)$} \\
\hline Age (year) & $1.020(0.995-1.046)$ & 0.113 & & \\
\hline Sex & & 0.626 & & \\
\hline Male & 1.00 (Reference) & & & \\
\hline Female & $0.810(0.347-1.890)$ & & & \\
\hline $\mathrm{BMI}(\mathrm{kg} / \mathrm{m} 2)$ & $1.013(0.932-1.102)$ & 0.756 & & \\
\hline KPS & $1.018(0.907-1.143)$ & 0.761 & & \\
\hline Gastric primary tumor location & & 0.045 & & 0.211 \\
\hline Proximal & 1.00 (Reference) & & 1.00 (Reference) & \\
\hline Middle & $0.772(0.374-1.596)$ & 0.485 & $1.052(0.472-2.344)$ & 0.901 \\
\hline Distal & $0.579(0.301-1.112)$ & 0.101 & $0.582(0.291-1.161)$ & 0.125 \\
\hline Total & $1.705(0.777-3.741)$ & 0.183 & $1.356(0.465-3.952)$ & 0.577 \\
\hline $\begin{array}{l}\text { Size of gastric primary tumor } \\
(\mathrm{cm})\end{array}$ & $0.989(0.914-1.069)$ & 0.778 & & \\
\hline Bormmann & & $<0.001$ & & 0.005 \\
\hline Mass & 1.00 (Reference) & & 1.00 (Reference) & \\
\hline Ulcerative & $0.860(0.261-2.830)$ & 0.803 & $0.957(0.279-3.285)$ & 0.944 \\
\hline Infiltrative ulcerative & $2.003(0.558-7.189)$ & 0.287 & $2.422(0.622-9.421)$ & 0.202 \\
\hline Diffuse infiltrative & $10.967(2.241-53.665)$ & 0.003 & $8.295(1.324-51.981)$ & 0.024 \\
\hline
\end{tabular}




\begin{tabular}{|c|c|c|c|c|}
\hline & \multicolumn{2}{|c|}{ Univariate } & \multicolumn{2}{|c|}{ Multivariate } \\
\hline & HR $(95 \% C I)$ & P-value & HR $(95 \% C I)$ & P-value \\
\hline $\begin{array}{l}\text { Degree of histologic } \\
\text { differentiation }\end{array}$ & & 0.365 & & \\
\hline Well or moderately & 1.00 (Reference) & & & \\
\hline Poorly or signet-ring cell & $1.288(0.744-2.229)$ & & & \\
\hline $\mathrm{T}$ & & 0.703 & & \\
\hline $\mathrm{T} 1$ & 1.00 (Reference) & & & \\
\hline $\mathrm{T} 2$ & $1.150(0.257-5.148)$ & 0.855 & & \\
\hline $\mathrm{T} 3$ & $1.966(0.437-8.857)$ & 0.379 & & \\
\hline $\mathrm{T} 4$ & $1.669(0.600-4.642)$ & 0.326 & & \\
\hline $\mathrm{N}$ & & 0.473 & & \\
\hline N0 & 1.00 (Reference) & & & \\
\hline N1 & $0.942(0.402-2.206)$ & 0.891 & & \\
\hline N2 & $1.551(0.693-3.469)$ & 0.285 & & \\
\hline N3 & $1.400(0.622-3.152)$ & 0.417 & & \\
\hline Type of liver metastases & & 0.445 & & \\
\hline Synchronous & 1.00 (Reference) & & & \\
\hline Metachronous & $0.767(0.388-1.516)$ & & & \\
\hline Interval of metachronous & $0.975(0.946-1.005)$ & 0.096 & & \\
\hline Number of liver metastases & & 0.937 & & \\
\hline Isolated metastases & 1.00 (Reference) & & & \\
\hline Multiple metastases & $0.979(0.579-1.656)$ & & & \\
\hline $\mathrm{H}$ & & 0.530 & & \\
\hline H1 & 1.00 (Reference) & & & \\
\hline $\mathrm{H} 2$ & $1.583(0.709-3.534)$ & 0.262 & & \\
\hline $\mathrm{H} 3$ & $1.086(0.630-1.873)$ & 0.766 & & \\
\hline Size of liver metastases $(\mathrm{cm})$ & $1.000(0.889-1.125)$ & 0.999 & & \\
\hline NLR & $1.025(0.818-1.285)$ & 0.828 & & \\
\hline CEA & 0.992(0.973-1.011) & 0.416 & & \\
\hline AFP & $1.016(0.985-1.048)$ & 0.313 & & \\
\hline Chemotherapy & & 0.514 & & \\
\hline Perioperative chemotherapy & 1.00 (Reference) & & & \\
\hline Postoperative chemotherapy & $1.209(0.684-2.135)$ & & & \\
\hline Hepatectomy & $0.553(0.329-0.929)$ & 0.025 & $0.560(0.312-1.004)$ & 0.052 \\
\hline RFA & $1.069(0.603-1.069)$ & 0.820 & & \\
\hline TACE & $1.558(0.923-2.631)$ & 0.097 & & \\
\hline
\end{tabular}

HR, hazard ratio; CI, confidence interval; NLR, neutrophil-to-lymphocyte ratio; CEA, carcinoembryonic antigen; AFP, alpha-fetoprotein 
The initial analysis of the entire cohort did not detect a significant difference between hepatectomy and palliative local treatments (RFA, TACE or both). Noticeably, the hepatectomy group included fewer patients with metachronous liver metastases, more patients with younger age or higher AFP levels compared with that of the palliative local treatment group. Therefore, we conducted PSM analysis to minimize these potential confusion. In the propensity model, we verified that hepatectomy was the optimal therapy for patients with GCLM.

However, hepatectomy is not suitable for every patient with GCLM. Unlike colorectal liver metastases, $[15,16]$ only a minority of GCLM patients are candidates for hepatic resection and most of them are synchronous GCLM patients. The severe adhesions in the upper abdominal organs caused by previous surgery often leads to high mortality and morbidity of patients who undergo metachronous resection. Therefore, it is crucial to identify suitable candidates for liver resection. According to our experience, we recommend that the indications for hepatectomy include the following: (a) preoperative imaging showing no signs of local aggression, peritoneal dissemination, or extrahepatic metastasis; (b) resectable primary gastric tumor and liver metastases, leaving a negative margin; and (c) acceptable hepatic function indicated by the serum liver function test panel. If hepatic resection is impossible to achieve because of the location, size or number of liver metastases, RFA and TACE should be considered.

RFA has been reported to have been used in well selected GCLM patients with solitary lesions of $<3 \mathrm{~cm}$ in diameter; [17, 18] particularly as a supplementary treatment for hepatectomy in cases with borderline resectability [19]. However, a study of a small sample size[20] reported that because of multiple intrahepatic recurrence, RFA is not recommended as an independent therapy for hepatic metastases from gastric cancer. RFA should therefore be considered more suitable for combination therapy.

Compared with systemic chemotherapy, TACE has the unique advantage for delivering high-concentration drugs to metastases as well as to control systemic toxicity. A previous study[21] involving a small sample size demonstrated the effectiveness of TACE for treating GCLM. In the present study, Kaplan-Meier analysis indicated that the efficacy of TACE was similar to that of RFA. However, TACE was significantly less expensive compared with RFA when administered to patients with metachronous GCLM. With more expanded indications, we believed that TACE may be more promising if included in standardized treatments for GCLM.

Unlike previous studies, [7, 22-24] we found here that only diffuse infiltration of the Borrmann classification independently predicted prognosis. Other factors, such as serosal invasion of the primary gastric cancer, number and size of hepatic metastases, and tumor-free margin did not significantly affect prognosis. This may be a reasonable result considering the development and standardization of curative resection. Moreover, multidisciplinary and comprehensive treatments have a major impact on the natural course of disease, which significantly reduces the influence of patients' clinicopathological characteristics.

We verified findings supported by the research of Kinoshita et al [7]. and Cheon et al. [9], who found that patients with metachronous GCLM survived significantly

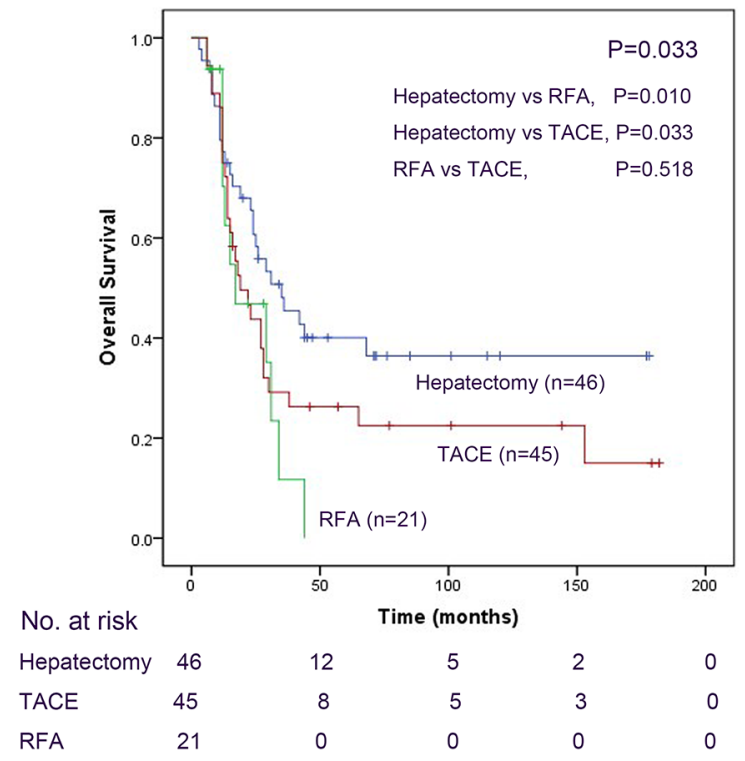

Figure 2: We compared the long-term outcomes of patients who received a single local treatment (hepatectomy, 46 patients; TACE, 45 patients; and RFA, 21 patients) using the Kaplan-Meier method and the log-rank test to evaluate the differences between groups. 
Table 4: Financial costs of treatment

\begin{tabular}{lcc}
\hline & Average cost (RMB, yuan) & P-value \\
\hline Synchronous & & 0.164 \\
Gastrectomy+hepatectomy & $81488 \pm 17161$ & $118584 \pm 60365$ \\
Gastrectomy+RFA & $113383 \pm 21962$ \\
Gastrectomy+hepatectomy+RFA & \\
Metachronous & $39215 \pm 12598$ \\
TACE & $95250 \pm 42129$ \\
RFA & $88265 \pm 38287$ \\
TACE+RFA & $\mathbf{0 . 0 1 4}$ \\
\hline
\end{tabular}

Bold value is statistically significant $(\mathrm{P}<0.05)$. TACE, transarterial chemoembolization; RFA, radiofrequency ablation

A
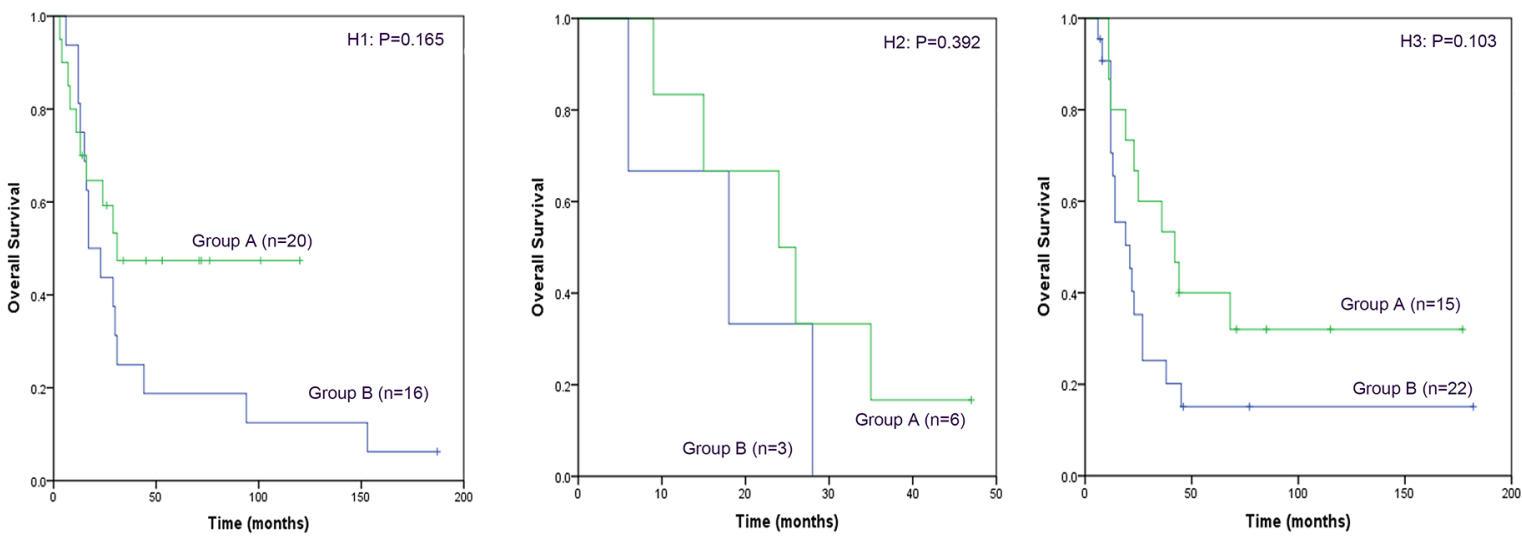

B
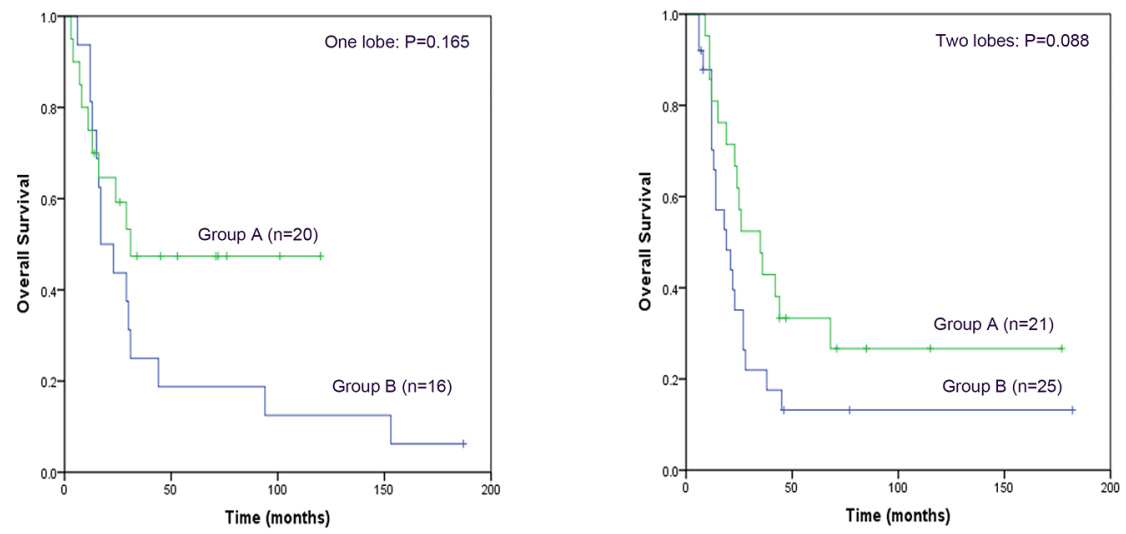

Figure 3: Cumulative overall survival was analyzed using the Kaplan-Meier method, and the differences in survival curves among the groups were compared using the log-rank test. (A) The long-term outcomes of patients in Group A and Group B were separately compared in the H1, H2 and H3 subgroups. (B) The long-term outcomes of patients in Group A and Group B were separately compared with respect to different degrees of liver metastases (one lobe vs two lobe) subgroups. 
longer compared with those with synchronous GCLM (Supplementary Figure 1). And another interesting negative conclusion got our attention. We proved that the $\mathrm{H}$ classification did not significantly influence OS (Supplementary Figure 2), which is in stark contrast to the findings of our preliminary study [25]. Hepatectomy should be attempted regardless of the number of liver lesions, provided that all the metastases can undergo $\mathrm{R} 0$ resection. We believe that this novel conclusion is inspiring, because our findings show promise for providing more therapeutic opportunities for patients with $\mathrm{H} 2$ or $\mathrm{H} 3$ liver metastases.

The scarcity of patients and the diversification of chemotherapy strategies makes it difficult to assess the effectiveness of perioperative chemotherapy. Nevertheless, preoperative chemotherapy should be carefully considered, because it theoretically helps to identify non-responders and assist the preparation of alternative strategies when surgery is futile.

Expect for the traditional local treatments (surgery, TACE and RFA), the development of radiological and imaging techniques makes radiotherapy an alternative option for patients with GCLM who have contraindications for these treatments, such as severe cirrhosis, tumors wrapped around a vulnerable structure or a complication with underlying diseases. Intensity modulated radiotherapy, the next-generation 3-dimensional conformal radiation therapy, potentially delivers higher doses to improve control and decreases toxicity by limiting dose to normal structures [26]. Volumetric modulated arc therapy, another new radiation technique, can achieve highly conformal dose distributions on target volume coverage and sparing of normal tissues [27].

The present study has several limitations. First, its retrospective nature is prone to potential bias. Even a careful designed PSM analysis cannot completely avoid bias. Second, the selection of therapy mainly depended on doctors' and patients' preferences. The analysis of financial costs shows that multidisciplinary synthetic therapy for GCLM is relatively expensive. With the exception of the indications for local treatment, there are other requirements, including a patient's understanding of treatment options for late-stage cancer and economic sustainability. Another limitation is that the initial cases were from a single institution, which reduces the generalizability of the results. Therefore, more studies involving large-scale samples from multiple centers are required to further confirm the conclusions.

In summary, gastrectomy with D2 lymph node dissection is well accepted by certain patients with advanced gastric cancer, and hepatectomy is therefore the optimal local treatment for liver metastases when surgical $\mathrm{R} 0$ resection is intended. If patients are not appropriate for hepatectomy, palliative local treatments such as TACE and RFA are recommended. In our experience, TACE is an acceptable method with relatively high cost-effectiveness.

\section{METHODS}

\section{Patients}

The application of multidisciplinary synthetic therapy at the Chinese People's Liberation Army (PLA) General Hospital, Beijing, China was initiated in January 2001. Since then, the prospective database named the Gastric Cancer with Liver Metastasis Sub-database (GCLM-SD) was developed. The GCLM-SD collects all patients with GCLM who accept multidisciplinary and comprehensive treatments strategies based on gastrectomy and local treatment options for liver metastases. Patient demographics, clinicopathological features of the primary gastric tumor and liver metastases, treatment information, perioperative parameters and survival status are recorded in the database.

By the end of 2015, 1092 gastric cancer patients with liver metastases were diagnosed at the Chinese PLA Hospital. Of all these patients, 597 patients did not received gastrectomy, 279 patients received gastrectomy but no local treatments for liver metastases. Patients were included if they met the criteria as follows: i) liver-only metastases from gastric cancer at the time of diagnosis detected abdominal ultrasonography combined with magnetic resonance imaging or computed tomography, pathological examination or surgical exploration, ii) absence of untreated second primitive malignancies before surgery, and iii) received curative gastrectomy with D2 lymph node dissection and local treatments, including hepatectomy, RFA or TACE for liver metastases. Patients were excluded if they were receiving treatment for other serious underlying diseases or malignant tumors, if they were noncompliant, or unable to complete follow-up. Accordingly, 119 patients were eligible for inclusion and were divided into Group A (46, curative hepatectomy) and Group B (73, palliative local treatments: 21, RFA; 45, TACE; 7, combined RFA and TACE).

All enrolled patients gave their informed consent. This study was approved by the institutional review board of the Chinese People's Liberation Army General Hospital. We conducted follow-up during outpatient visits or by telephone. OS was calculated from the day of diagnosis of GCLM to the day of death or to December 2016, the last follow-up date.

\section{Treatments}

All the included patients underwent curative gastrectomy with D2 lymph node dissection. Subtotal gastrectomy was indicated for distal gastric cancer. For proximal gastric cancer or tumors involving more than one section of the entire stomach, proximal gastrectomy or total gastrectomy was preferred. All surgeries were performed with adequate margins $(\geq 5 \mathrm{~cm})$ using the Billroth I, Billroth II or Roux-en-Y techniques for 
reconstruction. After surgery, resected specimens were routinely processed for pathological assessment. Hepatectomy was performed only when surgical R0 resection was intended. For patients with synchronous hepatic metastases, hepatectomy was simultaneously performed with gastrectomy. Alternatively, RFA, TACE, or both were performed as alternative therapeutic procedures to patients with unresectable liver metastases. Here the objective was to achieve maximal cytoreduction according to specific conditions. For example, for patients who had undergone a previous abdominal operation for another disease, or tumor recurrence after radical resection, it is extremely difficult to perform hepatectomy because of severe adhesions. RFA was performed in some cases where metastases were so extensive that an insufficiently functioning liver remained after R0 resection. TACE was considered when the location of liver metastases was inconvenient for surgery or RFA, such as those close to the hepatic hilum, subphrenic space, or gall-bladder. Chemotherapy was allowed before or after surgery. Three-drug or two-drug cytotoxic regimens were administered to patients with KPS scores $>80$ who were subject to frequent toxicity evaluations. Because of rapid advances in the development of chemotherapeutics, many combinations of these agents were proposed. However, most regimens employ 5-fluorouracil based regimens, with the next most frequently used drugs being platinum compounds, docetaxel and epirubicin. All patients selected their multidisciplinary treatments after receiving a thorough explanation of the risks and possible alternatives, including the financial costs.

\section{Criteria}

The definition of tumor TNM-staging was based on the 3rd English Edition of the Japanese Classification of Gastric Carcinoma.[28] The size of the primary gastric tumor refers its maximal diameter. Tumor location was considered "total" if more than one section of the entire stomach was involved. Information regarding the degree of histologic differentiation was obtained from the pathological report, including well differentiated, moderately differentiated, poorly differentiated and signetring cell carcinoma. The NLR was calculated as follows: $\mathrm{NLR}=$ absolute neutrophil count/absolute lymphocyte count [29].

\section{Propensity score matching analysis}

To investigate the association between treatment selection and long-term outcomes in an observational, non-randomized study, PSM analysis was employed to overcome possible bias in selecting patients. Possible variables associated with the selection of treatment, including age, sex, BMI, KPS scores, primary gastric tumor location, size of gastric primary tumor, Bormmann type, degree of histologic differentiation, depth of invasion ( $\mathrm{T}$ stage), lymph node metastasis ( $\mathrm{N}$ stage) and characteristics of liver metastases (type, number, distribution and size) were comprehensively analyzed in the baseline comparisons. Variables associated with statistically significant differences $(\mathrm{P}<0.05)$ were included in the PSM analysis. A one-to-one matching requirement via the nearest-neighbor matching algorithm without replacement was performed to select matched pairs of patients. The analysis was conducted by using $\mathrm{R}$ statistical software, version 3.2.1.

\section{Other statistical analyses}

Continuous variables of the two groups were checked for normality of distribution using the one-sample Kolmogorov-Smirnov test, and compared using analysis of variance (Student's t-test or the Mann-Whitney U-test). Binomial and categorical data were evaluated by using cross-linked tables and the Pearson chi-squared test or the 2-tailed Fisher's exact test. Characteristics influencing survival were identified by means of univariate and multivariate analyses using the Cox proportional hazards model (backward stepwise entry, 0.05; removal, 0.10). Cumulative OS was analyzed using the Kaplan-Meier method, and the differences in survival curves among groups were compared using the log-rank test. Statistical significance was defined as $\mathrm{P}<0.05$ (two-sided). These statistical analyses were performed using SPSS software (Version 19.0; SPSS Inc., Chicago, IL, USA).

\section{Abbreviations}

GCLM, liver metastasis from gastric cancer
RFA, radiofrequency ablation
TACE, transarterial chemoembolization
KPS, Karnofsky Performance Scale
NLR, neutrophil to lymphocyte ratio
CEA, carcinoembryonic antigen
AFP, alpha-fetoprotein
OS, overall survival
OST, overall survival time
BMI, body mass index
HR, hazard ratio
CI, confidence interval

\section{Author contributions}

Jiyang Li and Kecheng Zhang participated in conception and design of the study and drafting the manuscript. Jiyang Li, Jianxin Cui, Yunhe Gao and Hongqing $\mathrm{Xi}$ analyzed and interpreted the data; Hongqing $\mathrm{Xi}$, Jianxin Cui, Wenquan Liang and Aizhen Cai collected and assembled the data and conducted the follow-up examinations; Lin Chen and Bo Wei participated in the study design and revision of the manuscript, and gave final 
approval of the version to be published. All authors read and approved the final manuscript.

\section{ACKNOWLEDGMENTS}

The authors are grateful to all the patients who contributed data to this study. This work was funded partly by the National Nature Science Foundation of China (No. 81672319, 81602507), the Major State Basic Research Development Program of China (2014CBA02002), the Beijing Municipal Science and Technology Plan projects (Z161100000516237), and the Chinese People's Liberation Army General Hospital Medical Big Data Project (No.2016MBD-012).

\section{CONFLICTS OF INTEREST}

The authors have declared no conflicts of interest.

\section{REFERENCES}

1. Torre LA, Bray F, Siegel RL, Ferlay J, Lortet-Tieulent J, Jemal A. Global cancer statistics, 2012. CA Cancer J Clin. 2015; 65: 87-108. doi: 10.3322/caac.21262.

2. Kamangar F, Dores GM, Anderson WF. Patterns of cancer incidence, mortality, and prevalence across five continents: defining priorities to reduce cancer disparities in different geographic regions of the world. J Clin Oncol. 2006; 24: 2137-50. doi: 10.1200/JCO.2005.05.2308.

3. Martella L, Bertozzi S, Londero AP, Steffan A, De Paoli P, Bertola G. Surgery for liver metastases from gastric cancer: a meta-analysis of observational studies. Medicine (Baltimore). 2015; 94: e1113.

4. Romano F, Garancini M, Uggeri F, Degrate L, Nespoli L, Gianotti L, Nespoli A, Uggeri F. Surgical treatment of liver metastases of gastric cancer: state of the art. World J Surg Oncol. 2012; 10: 157. doi: 10.1186/1477-7819-10-157.

5. Garancini M, Uggeri F, Degrate L, Nespoli L, Gianotti L, Nespoli A, Uggeri F, Romano F. Surgical treatment of liver metastases of gastric cancer: is local treatment in a systemic disease worthwhile? HPB (Oxford). 2012; 14: 209-15. doi: 10.1111/j.1477-2574.2011.00428.x.

6. Ambiru S, Miyazaki M, Ito H, Nakagawa K, Shimizu H, Yoshidome H, Shimizu Y, Nakajima N. Benefits and limits of hepatic resection for gastric metastases. Am J Surg. 2001; 181: 279-83.

7. Kinoshita T, Kinoshita T, Saiura A, Esaki M, Sakamoto H, Yamanaka T. Multicentre analysis of long-term outcome after surgical resection for gastric cancer liver metastases. Br J Surg. 2015; 102: 102-7.

8. Kim KH, Lee KW, Baek SK, Chang HJ, Kim YJ, Park DJ, Kim JH, Kim HH, Lee JS. Survival benefit of gastrectomy +/- metastasectomy in patients with metastatic gastric cancer receiving chemotherapy. Gastric Cancer. 2011; 14: 130-8.
9. Cheon SH, Rha SY, Jeung HC, Im CK, Kim SH, Kim HR, Ahn JB, Roh JK, Noh SH, Chung HC. Survival benefit of combined curative resection of the stomach (D2 resection) and liver in gastric cancer patients with liver metastases. Ann Oncol. 2008; 19: 1146-53.

10. Kodera Y, Fujitani K, Fukushima N, Ito S, Muro K, Ohashi N, Yoshikawa T, Kobayashi D, Tanaka C, Fujiwara M. Surgical resection of hepatic metastasis from gastric cancer: a review and new recommendation in the Japanese gastric cancer treatment guidelines. Gastric Cancer. 2014; 17: 20612. doi: 10.1007/s10120-013-0299-x.

11. Zacherl J, Zacherl M, Scheuba C, Steininger R, Wenzl E, Muhlbacher F, Jakesz R, Langle F. Analysis of hepatic resection of metastasis originating from gastric adenocarcinoma. J Gastrointest Surg. 2002; 6: 682-9.

12. Hofer S, Oberholzer C, Beck S, Looser C, Ludwig C. Ultrasound-guided radiofrequency ablation (RFA) for inoperable gastrointestinal liver metastases. Ultraschall Med. 2008; 29: 388-92.

13. Vogl TJ, Gruber-Rouh T, Eichler K, Nour-Eldin NE, Trojan J, Zangos S, Naguib NN. Repetitive transarterial chemoembolization (TACE) of liver metastases from gastric cancer: local control and survival results. Eur J Radiol. 2013; 82: 258-63. doi: 10.1016/j.ejrad.2012.10.006.

14. Austin PC. An introduction to propensity score methods for reducing the effects of confounding in observational studies. Multivariate Behav Res. 2011; 46: 399-424. doi: 10.1080/00273171.2011.568786.

15. de Jong MC, Pulitano C, Ribero D, Strub J, Mentha G, Schulick RD, Choti MA, Aldrighetti L, Capussotti L, Pawlik TM. Rates and patterns of recurrence following curative intent surgery for colorectal liver metastasis: an international multi-institutional analysis of 1669 patients. Ann Surg. 2009; 250: 440-8. doi: 10.1097/ SLA.0b013e3181b4539b.

16. Choti MA, Sitzmann JV, Tiburi MF, Sumetchotimetha W, Rangsin R, Schulick RD, Lillemoe KD, Yeo CJ, Cameron JL. Trends in long-term survival following liver resection for hepatic colorectal metastases. Ann Surg. 2002; 235: 759-66.

17. Chen J, Tang Z, Dong X, Gao S, Fang H, Wu D, Xiang $\mathrm{D}$, Zhang S. Radiofrequency ablation for liver metastasis from gastric cancer. Eur J Surg Oncol. 2013; 39: 701-6. doi: 10.1016/j.ejso.2013.03.023.

18. An JY, Kim JY, Choi MG, Noh JH, Choi D, Sohn TS, Kim S. Radiofrequency ablation for hepatic metastasis from gastric adenocarcinoma. Yonsei Med J. 2008; 49: 1046-51. doi: 10.3349/ymj.2008.49.6.1046.

19. Dittmar Y, Altendorf-Hofmann A, Rauchfuss F, Gotz M, Scheuerlein H, Jandt K, Settmacher U. Resection of liver metastases is beneficial in patients with gastric cancer: report on 15 cases and review of literature. Gastric Cancer. 2012; 15: 131-6.

20. Kim HO, Hwang SI, Hong HP, Yoo CH. Radiofrequency ablation for metachronous hepatic metastases from gastric 
cancer. Surg Laparosc Endosc Percutan Tech. 2009; 19: 208-12. doi: 10.1097/SLE.0b013e3181a033d7.

21. Wang YY, Zhang W, Qian S, Liu R, Kan ZX, Wang JH. The effect of locoregional transarterial infusion chemotherapy on liver metastasis after gastric cancer resection. J Int Med Res. 2012; 40: 1141-8.

22. Ochiai T, Sasako M, Mizuno S, Kinoshita T, Takayama T, Kosuge T, Yamazaki S, Maruyama K. Hepatic resection for metastatic tumours from gastric cancer: analysis of prognostic factors. Br J Surg. 1994; 81: 1175-8.

23. Miyazaki M, Itoh H, Nakagawa K, Ambiru S, Shimizu H, Togawa A, Shiobara M, Ohtsuka M, Sasada K, Shimizu Y, Yoshioka S, Nakajima N, Suwa T, et al. Hepatic resection of liver metastases from gastric carcinoma. Am J Gastroenterol. 1997; 92: 490-3.

24. Okano K, Maeba T, Ishimura K, Karasawa Y, Goda F, Wakabayashi H, Usuki H, Maeta H. Hepatic resection for metastatic tumors from gastric cancer. Ann Surg. 2002; 235: 86-91.

25. Liu J, Li JH, Zhai RJ, Wei B, Shao MZ, Chen L. Predictive factors improving survival after gastric and hepatic surgical treatment in gastric cancer patients with synchronous liver metastases. Chin Med J (Engl). 2012; 125: 165-71.

26. McIntosh A, Hagspiel KD, Al-Osaimi AM, Northup P, Caldwell S, Berg C, Angle JF, Argo C, Weiss G, Rich TA. Accelerated treatment using intensity-modulated radiation therapy plus concurrent capecitabine for unresectable hepatocellular carcinoma. Cancer. 2009; 115: 5117-25. doi: 10.1002/cncr.24552.

27. Poulsen PR, Worm ES, Petersen JB, Grau C, Fledelius W, Hoyer M. Kilovoltage intrafraction motion monitoring and target dose reconstruction for stereotactic volumetric modulated arc therapy of tumors in the liver. Radiother Oncol. 2014; 111: 424-30. doi: 10.1016/j.radonc.2014.05.007.

28. Japanese Gastric Cancer Association. Japanese classification of gastric carcinoma: 3rd English edition. Gastric Cancer. 2011; 14: 101-12. doi: 10.1007/s10120-011-0041-5.

29. Grenader T, Waddell T, Peckitt C, Oates J, Starling N, Cunningham D, Bridgewater J. Prognostic value of neutrophil-to-lymphocyte ratio in advanced oesophagogastric cancer: exploratory analysis of the REAL-2 trial. Ann Oncol. 2016; 27: 687-92. doi: 10.1093/annonc/mdw012. 